\title{
Online information use on health/illness by relatives of hospitalized premature infants
}

\author{
Uso de informações on-line sobre saúde/doença por famílias de prematuros hospitalizados \\ Uso de información online sobre salud/enferencia por famílias de prematuros hospitalizados
}

\author{
Vanessa Ferreira de Lima' \\ ORCID: 0000-0002-8306-7790 \\ Verônica de Azevedo Mazza" \\ ORCID: 0000-0002-1264-7149 \\ Carmen Gracinda Silvan Scochi'
ORCID: 0000-0001-5865-9711 \\ Luciana Schleder Gonçalves" \\ ORCID: 0000-0003-3105-3028
}

'Universidade de São Paulo. Ribeirão Preto, São Paulo, Brazil.

"Universidade Federal do Paraná. Curitiba, Paraná, Brazil.

How to cite this article:

Lima VF, Mazza VA, Schochi CGS, Gonçalves LS. Online information use on health/illness by relatives of hospitalized premature infants. Rev Bras Enferm. 2019;72(Suppl 3):79-87. doi: http://dx.doi.org/10.1590/0034-7167-2018-0030

Corresponding Author:

Verônica de Azevedo Mazza

E-mail: mazzas@ufpr.br

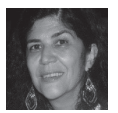

Submission: 06-19-2018 Approval: 02-01-2019

\begin{abstract}
Objective: To analyze the use of online information on health/illness by relatives of premature infants admitted to the Neonatal Intensive Care Unit. Method: Exploratory, qualitative study conducted at a Neonatal Intensive Care Unit from a University Hospital in the state capital of southern Brazil, with 33 relatives of hospitalized premature infants. The data were collected through a semi-structured interview and were submitted to thematic analysis, with the aid of the software Interface de R pour les Analyses Multidimensionnelles de Textes et de Questionnaires (IRAMUTEQ ${ }^{\circ}$ ). Results: From the data analysis, two thematic categories emerged: Online information on health/illness researched by relatives; and Online sources of information consulted by relatives. Final considerations: Health professionals need to consider the use of online information by relatives in the care process, adding it in their practice in relation to the informational needs presented, and stimulating spaces for dialogue about the data found.

Descriptors: Consumer Health Information; Family; Infant, Premature; Neonatal Intensive Care Units; Neonatal Nursing.
\end{abstract}

\section{RESUMO}

Objetivo: Analisar o uso de informações on-line sobre saúde/doença por famílias de prematuros internados em Unidade de Terapia Intensiva Neonatal. Método: Estudo exploratório, de abordagem qualitativa, realizado na Unidade de Terapia Intensiva Neonatal de um Hospital Universitário situado na capital de um estado da região sul do Brasil, com 33 familiares de prematuros internados. Os dados foram coletados por meio de entrevista semiestruturada e foram submetidos à análise temática, com auxílio do software Interface de $R$ pour les Analyses Multidimensionnelles de Textes et de Questionnaires (IRAMUTEQ). Resultados: Da análise dos dados, emergiram duas categorias temáticas: Informações on-line de saúde/doença pesquisadas pelas famílias; e Fontes de informação on-line consultadas pelas famílias. Considerações finais: Os profissionais de saúde precisam considerar o uso das informações on-line pelas famílias no processo de cuidar, atendo-se em sua prática para as necessidades informativas apresentadas, e estimulando espaços de diálogo sobre os dados encontrados.

Descritores: Informação de Saúde ao Consumidor; Família; Recém-Nascido Prematuro; Unidades de Terapia Intensiva Neonatal; Enfermagem Neonatal.

\section{RESUMEN}

Objetivo: Analizar el uso de información online sobre salud/enfermedad por familias de prematuros internados en Unidad de Terapia Intensiva Neonatal. Método: Estudio exploratorio, de abordaje cualitativo, realizado en la Unidad de Terapia Intensiva Neonatal de un Hospital Universitario situado en la capital de un estado de la región sur de Brasil, con 33 familiares de prematuros internados. Los datos fueron recolectados por medio de entrevistas semiestructuradas y fueron sometidos al análisis temático, con ayuda del software Interface de $R$ pour les Analyses Multidimensionnelles de Textes et de Questionnaires (IRAMUTEQ). Resultados: Del análisis de los datos, surgieron dos categorías temáticas: Información online de salud/ enfermedad investigadas por las familias; y Fuentes de información online consultadas por las familias. Consideraciónes finales: Los profesionales de la salud deben considerar el uso de las informaciones online por las familias en el proceso de cuidar, atendiendo en su práctica a las necesidades informativas presentadas, y estimulando espacios de diálogo sobre los datos encontrados.

Descriptores: Información de Salud al Consumidor; Familia; Recién Nacido Prematuro; Unidades de Terapia Intensiva Neonatal; Enfermería Neonatal. 


\section{INTRODUCTION}

Internet is being widely used as a source of health information by individuals. Among the most frequently searched online users are pregnant women, parents of children with chronic conditions, and family members of infants who need surgical intervention ${ }^{(1)}$.

The expressive use can be explained by the considerable increase in Internet access and mobile telephony. Data from the survey "TIC Domicílios 2015" describe that 102 million Brazilians are Internet users; 34.1 million households in the country have access to this; and the smartphone is the most used ${ }^{(2)}$.

Among the resources available online, family members can use websites, forums and blogs, trying to understand and complement the experience of having a child hospitalized in a Neonatal Intensive Care Unit (NICU) $)^{(3)}$. In addition, applications ${ }^{(4)}$ and text messages have been commonly used to access and spread information related to health care ${ }^{(5)}$.

Family members access the Internet to find information about illnesss or help in understanding them ${ }^{(6)}$; to seek data related to parenting, such as social support, sharing information, and offering and receiving support regarding the experience of a particular health condition ${ }^{(7)}$; to look for experiences similar to those they are experiencing ${ }^{(8)}$, because from the data obtained, they can clarify other members of the family ${ }^{(9)}$. And sometimes, they may attribute more value to this information than those coming from the knowledge of the more experienced members of the family unit ${ }^{(8)}$.

With the realization of virtual searches, individuals feel empowered and are to some extent controlling the situation faced ${ }^{(10)}$. Some parents report feeling of relief and decreased anxiety ${ }^{(11)}$.

However, the breadth of content on the internet, without restriction to the specific situation of the child, can cause negative feelings and stress to the family. However, these feelings are reduced from the moment they can discern the correct information regarding the child's diagnosis, controlling their emotions and the situation they are experiencing ${ }^{(12)}$.

Surfing on the Internet goes beyond simple searches and finds only definitions and symptoms. Parents can be directed to specific information, for example: how the person living with a particular illness coexists, what are their limitations and feelings when they experience health condition. Thus, when they find information in a satisfactory way, they tend to indicate the websites and tools used for other individuals with the same experiences ${ }^{(11)}$.

When it comes to care, the increasing availability of information can aid in greater patient autonomy, or in the case of children, of those responsible. With the access, the professionals find patients and family members more prepared to create questions, since they are based on additional knowledge, being up to the specialists the data interpretation found by individuals ${ }^{(13)}$.

In some cases, Internet researches are due to the lack of guidelines by professionals ${ }^{(13)}$, with part of them carried out without being able to consult with a specialist. This can be caused by geographical barriers that hinder access or due to the need for information at indiscriminate times, in which there is no expedient of specialists to be questioned ${ }^{(11)}$.

In addition, the family seeks online data as a way to complement the knowledge of professionals, not to replace it; since the elements sought help in the care provided at home. Therefore, it is important to guide the use of reliable resources to support such care ${ }^{(14)}$ and guide subjects in relation to health information available in that environment ${ }^{(10)}$.

It is considered that the analysis of how online information on health/illness is used by relatives of premature infants hospitalized in NICU can subsidize professionals to improve the care provided. This analysis can also aid in the planning and implementation of interventions that can meet the information needs of family members. From this, experts can be encouraged to subsidize the development of tools that provide authentic and intelligible content.

There are still unknown studies published in Brazil that investigated the use of online information by family members of premature infants or that were developed during the hospitalization of infants in a NICU.

In this setting, the focus of interest of this investigation is located and it is questioned: how relatives of premature infants hospitalized in NICU have used online information on health/illness?

\section{OBJECTIVE}

To analyze the use of online information on health/illness by relatives of premature infants hospitalized in a NICU.

\section{METHOD}

\section{Ethical aspects}

Ethical precepts were respected, according to Resolution $466 / 2012$ of the Brazilian Commission for Research Ethics of the National Health Council. The study was approved by the Research Ethics Committee (CEP - Comitê de Ética em Pesquisa) of Health Sciences of the Universidade Federal do Paraná. The study was also approved by the CEP of the participating institution.

Participants' anonymity was preserved by using alphanumeric identification (Int - interview, followed by a numerical order from 01 to 30). All names mentioned during the interviews were changed by pseudonyms.

\section{Type of study}

This is an exploratory study, with a qualitative approach.

\section{Methodological procedures}

The study's preparation sought to follow the steps recommended by COREQ (Critérios Consolidados para Relatar uma Pesquisa Qualitativa - Consolidated Criteria for Reporting a Qualitative Research), which is a research guide composed of 32 items considered necessary for the development of qualitative studies ${ }^{(15)}$.

\section{Study setting}

The study was conducted in the NICU of a University Hospital in the capital of a state in the southern region of Brazil. Study participants were 33 relatives of premature infants hospitalized, invited by personal invitation and printed information prepared by the researchers, made available ten days before the beginning 
of data collection and remaining in the NICU until the end of this period. It was emphasized that there were no refusals to participate in the study. All participants who met the inclusion criteria were invited and accepted to be part of this. There were no withdrawals from participants.

The following criteria were established for inclusion in the study to be familiar with a preterm hospitalized 10 days or more in the NICU; have internet access and be over 18 years old. As an exclusion criterion, it was established: have communication difficulties that made it impossible to answer the questions.

\section{Collection and organization of data}

The data collection took place from April to July 2016, through a semi-structured interview. The interview included family and premature infant characterization, and the following guiding questions related to the use of online information on health/illness by relatives of premature infants hospitalized in a NICU: Do you use information from the internet to find out about your child's health/illness situation? What information about your child's health/ illness condition do you look for on the internet? Which websites do you use and with what words or terms?

Previously, 13 pilot interviews were carried out to refine the data collection tool. During the first five interviews, it was found that some family members used the Internet to search for data on the condition of prematurity of another child, not the one hospitalized in the period of data collection. Therefore, some questions were adapted to address the information needs related to both hospitalizations, testing them in a second pilot with eight relatives, in order to verify their applicability. It should be noted that the data from the pilot interviews were not included in the analysis of this study.

Thirty-three family members participated in the study, and 30 interviews were performed, since three of them occurred with fathers and mothers, concomitantly. All were done in the NICU, in a private place that consisted of a separate room, which is used for storage of materials and for private conversations between family and staff.

The team that made the interlocutions was composed by the researcher and two previously trained research assistants, who were not present in all interviews. The number of interviewers was necessary to meet the availability of relatives at different times in order to reach the largest number of participants. Each of them entered the NICU according to their availability of time, made the family's approach the invitation to participate and conducted the interview at a date and time agreed.

Interviews lasted, on average, 20 minutes. They were recorded in audio by means of authorization, transcribed in their entirety and later returned to the participants for reading and approval of the described content. However, 17 of the 33 participants did not perform this because of premature infant death and hospital discharge. There was an attempt to contact family members for return, comments and approval of the content, but without success.

\section{Data analysis}

The data were submitted to the thematic analysis based on data sense extraction of the text, resulting from the interviews, enabling the researcher to reflect on these and the deepening in search of their meaning ${ }^{(16)}$. The software Interface de $R$ pour les Analyses Multidimensionnelles de Textes et de Questionnaires (IRAMUTEQ ${ }^{\circ}$ ) was used to help codify, organize and separate the information found, since it provides vocabulary organizationin a clear and comprehensible way ${ }^{(17)}$.

For thematic analysis, we followed the methodological framework proposed by Creswell ${ }^{(16)}$, which includes six steps: organization and preparation of the data, in which the interviews were transcribed in full, codified and structured in a textual corpus format (a cluster of texts expressing a particular theme); reading of all the data to obtain the general perception of the ideas expressed by the interviewees; coding the data by arranging the information in text segments (TS) (dividing the text into the average size of three lines) and grouping them into categories established based on the similarity between the sentences found, which resulted from the processing of the data in the IRAMUTEQ ${ }^{\circ}$; description of the data, using the coding previously assigned to establish the categories, in order to reflect the main results of the study; representation of the analysis by means of categories that emerged from the themes indicated in the classes coming from the software; and interpretation of the data with the details of interviews and comparison of these with the findings found in the literature.

As for the data resulting from the interviews, the software processed the textual corpus formed by 30 interviews, classified TS according to the vocabulary. We present four classes that are related to each other, being one of them chosen as object for analysis of this study. In this study, TS frequencies, with a higher frequency, with a larger chi-square value and $p<0.001$, consisted of: website, remember, use, Google, health/illness, gestation, condition, search, name, access, Babycenter, week, seek, appear, put, search, a lot, pregnancy, open, websites, YouTube, video, write, water breaking, hypothyroidism, typing and finger.

From the referred class, two thematic categories emerged named according to the meaning of the reports of the participants, entitled: Online information on health/illness researched by relatives; and Online sources of information consulted by relatives, as follows.

\section{RESULTS}

There were 29 female participants and four male participants, aged between 18 and 47.15 were married, and 10 completed High School. The diversity of the latter from incomplete elementary school to full Higher Education with specialization was highlighted.

The family income of most relatives (20) consisted of one to three minimum wages. The time of hospitalization of preterm infants in the NICU ranged from 10 to 86 days. According to the interviewees, the most used resource to access the internet was the mobile phone (31).

As regards the two thematic categories resulting from the processing of the data, their descriptions and reports are presented.

\section{Online information on health/illness researched by relatives}

Family members searched for information on various topics. These searches are related to situations of the gestational period such as: growth and development of the fetus during pregnancy, experiences different from those experienced in previous pregnancies, 
pathologies and maternal intercurrences, labor, procedures, such as cervical cerclage, and medications used, as explained:

I always used the first word to search, like "flow centralization" I put "flow centralization" and brought several websites talking about it. Outra coisa é o diabetes gestacional. Week by week [referring to fetal development] you put it like this: pregnancy. For example, I wanted to know what happens in the 30th week. Put 30 weeks of gestation first, the website already had an idea of how the baby was already. (Int 20)

I looked for DHEG [Doença Hipertensiva Especifica da Gravidez, Hypertensive IIIness of Pregnancy] and pre-eclampsia, which were the names given to me. (Int 13)

I looked for what to do when the water breaks, what procedures to take. I searched for what it was, and the doctors told me to take rest... (Int 08)

[...] since the beginning of gestation I have looked for a lot... [...] about what can and cannot do during pregnancy... [...] / researched a lot about labor on YouTube. I always kept looking normal birth, which, in the end, did not work. YouTube has enough video, quite explanation. (Int 22)

I searched about the infection I was in, if it was normal. As time passed, it grew and grew worse. I've looked a lot about it.. I've looked a lot into it.... [...] I looked into cervical cerclage, [...] And I also searched a lot about the medicines I used, every medicine they [doctors] went through I was looking for the effect and what position [that the baby was], everything... (Int 28)

In addition to the themes related to the gestational period, respondents searched the internet for content such as: pathologies and intercurrences with the newborn (NB); issues related to prematurity; child development; care of the newborn; rare syndromes; breastfeeding and relactation; procedures; equipment and medications used in the treatment of prematurity; and technical terms of little common sense, used by professionals during dialogues or in the medical record, as can be verified in the following excerpts:

I used it to search for the term doctors use. Congenital hypothyroidism, for example, sometimes we do not even know what it is, and the word 'congenital' appears. More or less the word that the doctors speak and not that we understand and try to search... (Int 01)

I used a lot of websites, put a premature infant for 33 weeks and everything that came I visited, put it on Google and read everything that appeared. Normally, I would type 'CPAP baby' [Continue Positive Airway Pressure], baby with one pound and that, in the case, it was 1,460 kilograms, that kind of thing... (Int 16)

I usually put into research what I really want to know, such as causes of apnea in premature or 29-week premature survival, 29-week premature sequel, ideal premature body weight... (Int 17)

[...] I was researching what I could do if I did not have a saturation apparatus to see [saturation]. They have websites that explain, for example, that you put the baby in the body and feel that he is breathing as his belly will swell and will decrease... (Int 02)
I looked for the flash, because you cannot take flash photography in children, babies, and water breaking. (Int 09)

[...] I accessed and looked for Edwards Syndrome and its summary.... (Int 03)

[...] when it was in relation to the medication, I put the name of the medicine and 'premature' later to know the effect of the medicine in premature infant, when it was in relation to the surgery also, PAD [Persistent Arterial Duct] in premature... [...] Regarding the relactation, I wrote this myself, relactation, because at first I was looking for decreased milk or premature breastfeeding... (Int 23)

\section{Online sources of information consulted by relatives}

Regarding the sources consulted online, part of the interviewees reported having knowledge about which portals were visited. The most visited website was BabyCenter.com, followed by YouTube, Yahoo Answers, Wikipedia and two blogs that provided pertinent content to that sought, demonstrated in the following reports:

Look, it's just that I searched Google for the websites that actually show up. Which I remember, one is this Babycenter and on Google I've seen that Yahoo Answers too. (Int 11)

[...] in pregnancy, I used the Babycenter a lot, and a lot! And Babycenter also helped us a lot, but this one of the illnesss ... I do not remember the name of the websites, that in fact you do not worry about the URL of the websites, you worry about the content. (Int 06)

I was looking for, had one that is Projeto Pequenos Guerreiros [Little Warriors Project], where I read the book that talks about premature infants and also has a whole pregnancy website, I do not know if it really is true, but it's that Babycenter... (Int 17)

[...] I always did research on YouTube, the videos that you understand best, that sometimes have doctors lecturing, have some testimonials... (Int 20)

Website with the best information, the worst I do not know, but the best, which is what I always get information and always gives me certainty, it's Wikipedia, if I'm not mistaken. (Int 03)

[...] of relationship, of lactation, it was a testimonial blog, I think it is: We have to talk about it, the name of the blog, and it talks about a girl who did relactation, but it was not a medical article. (Int 23)

On the other hand, a considerable portion of the family members emphasized ignorance of the sources used during Internet searches. They emphasized forgetfulness of which was the website consulted and the lack of care in relation to this one. In addition, most respondents were able to identify only the search tool employed, as the elocutions point out:

[...] I put bronchodysplasia on Google. This website I used, to tell you the truth, did not see the name, I read and saw that it appeared. l opened the website, if you ask me what it was it does not even cross my mind. (Int 04)

The website I used, now I do not remember, I accessed the website of the weeks of gestation, now I do not remember the website name exactly. I found this website through Google... (Int 18) 
Website with the best information... I do not remember what my daughter accessed, is what you put the name and click on the one you find most interesting. (Int 19)

[...] I found a website that publishes studies, like an electronic magazine. I do not remember the name, it is the medical one and has studies that are much more complete... (Int 22)

\section{DISCUSSION}

In the analysis of results, it was verified that the information researched online by family members alternated between themes pertinent to the gestational and postnatal period, which were related to both maternal and child health. In addition, growth and development of the NB, aspects involving prematurity and unknown technical terms generated worries and boosted the use of the internet, presenting themselves as themes sought in this medium.

In a systematic review that investigated the ways in which pregnant women used the internet to obtain information pertinent to pregnancy, the data showed that they researched health content related to fetal development, stages of pregnancy; nutrition; and stages of delivery ${ }^{(18)}$, which is in line with the results obtained for the gestational period.

Another study also points out that information sought by mothers, on the internet, is routinely related to the fetus. For example, the identification of gestational weeks and the growth in this period; referring to the newborn; child development; breastfeeding; nutrition, such as the period and correct introduction of solid food; and safety measures such as proper positioning of the child while sleeping ${ }^{(19)}$.

Due to children's needs and the new experiences of motherhood/paternity, family members lack information ${ }^{(20-21)}$. Soon, they routinely go to the internet, in search of elements that subsidize and strengthen the care to be provided to the $\mathrm{NB}^{(20)}$.

Ratifying the findings of this study, an investigation conducted in Midlands, UK with 27 parents, 10 doctors and 6 nurses, in order to explore the opinions of parents and professionals on the ideal content type, format and security of information available online on acute illness in childhood found that after diagnosis parents feel a need to know about symptoms associated with the pathologies and the reasons that led to their occurrence. Likewise, they want to know where, when and with whom they can get help ${ }^{(22)}$.

It is usual family members to carry out internet searches immediately after receiving the diagnosis, which are performed to confirm information received; discover the severity of the pathology; what is and how the course of the illness will occur; check the perceived symptoms when they should worry; and what measures can be employed to care for and assist the child ${ }^{(23)}$.

Relatives research information directed to the health needs presented by the child. In this respect, the virtual network is often used as an educational medium in which family members learn about pathologies, indicated treatments and care provided ${ }^{(24)}$. These data corroborate those found in this study, in which relatives performed online searches related to gestation, prepartum, delivery and puerperium, whether they were directed to the mother or to the NB.

With the myriad of health/illness information available on the internet, individuals can search for additional data or have not been offered by professionals. Therefore, it tends to research on subjects related to their health condition or a relative, such as intercurrences and care for improvement in the presented framework. It is also reinforced that, often, the subjects aim to receive indications of reliable websites and with adequate information coming from health professionals ${ }^{(25)}$.

In this context, nurses need to instruct family members in the search for online information, assessing their knowledge, as well as the needs related to the child's prognosis. They should consider the interpretations of the information they find, helping them to correlate with the illness of the newborn ${ }^{(26)}$; and also to guide them as to the possibility of being of poor quality, imprecise, with biased or outdated data ${ }^{(27)}$. In this case, indicating specialized websites and free access to the public can be of great value to patients and/or family members who need credible and good quality information ${ }^{(10)}$.

With regard to the knowledge of the sources of online information used by family members to obtain health/illness data, it should be noted that in this study only a fraction of individuals discerned the portal visited in the searches. In these cases, the use of the private baby-centered website BabyCenter.com, which provides content related to gestation, delivery and care with the NB, is identified and has an application, with information similar to the website. To a lesser extent, YouTube, Yahoo Answers, Wikipedia and two separate blogs dealing with matters relating to prematurity.

As to the identification of the sources used in the research, the findings of this study are reinforced by another study carried out with 49 women, aiming to explore how health information sources guide decision making among Hispanic mothers during the first 1000 days of life kid. They generate adequate sources of health information and communication strategies for future interventions. It was found that the interviewees referred to Google as the main search tool, BabyCenter.com as a frequently used website. The interviewees affirmed access to YouTube to watch videos on various topics related to gestation, childbirth and child care ${ }^{(19)}$, which is in line with the results obtained here.

BabyCenter.com is a commercial website, considered popular among pregnant women and puerperas and, in its interpretation, provides reliable content. This portal sends weekly emails about maternity issues and there is an exchange of experiences between users. In addition, the brand has an application to be used in smartphones ${ }^{(19)}$, commonly used by pregnant women to monitor the growth of the child and monitoring the formation of organs and the size of the body ${ }^{(28)}$.

Personalized information received through applications and other resources is valued by mothers, especially those who are using this type of tool for the first time. Platforms and applications with numerous functions that enable interactions with other individuals are appreciated. Many endorsed digital media that point to local services, such as specific groups of pregnant women or postpartum women so they can participate. Preference is given to accessing monitoring applications for healthy children, such as those that provide heart rate, body temperature and sleep monitoring ${ }^{(29)}$.

In a study conducted in the United Kingdom with parents (24 mothers and three parents) to investigate the use of information resources at home for decision-making in acute childhood illness, the interviewees' child health illness information. Parents considered this resource beneficial, when compared to 
other virtual media, because it allows the limitation of content, providing specific data and in quantity pertinent to what they want to know ${ }^{(23)}$.

Mobile devices are considered interesting by family members because they are agile and flexible due to the possibility of seeking information anytime, anywhere, even when they are taking care of their children, and doubts arise that need to be remedied quickly ${ }^{(29)}$.

Online health/illness information provides a practical aid in learning related to pregnancy, childbirth and maternity ${ }^{(29)}$, such as thermal applications and massages to facilitate intestinal motility ${ }^{(19)}$. In this regard, YouTube has been referred to as a portal in which countless videos on birth and child care can be found. It is favorable for allowing content to be viewed several times, unlike when they receive personal guidance ${ }^{(29)}$.

Results mentioned beforehand are similar to those found in this study, in which some interviewees reported visiting YouTube due to the explanatory videos that make it possible to acquire immediate knowledge and that eventually have health professionals explaining the topic of interest.

On several occasions, women choose to share their experiences on YouTube, expressing the experience of a certain situation, such as cases of previous abortions. In this way, they believe they benefit others by describing abnormal signs and symptoms, and also offer social support to those who have faced the same event ${ }^{(19)}$.

A study conducted in Sydney, Australia with 36 women on the use and use of digital media to obtain information on pregnancy and early motherhood revealed that the ability to exchange experiences, advice and share personal data through social media and applications was a positive aspect, being emphasized by mothers. Information exchange sometimes results in friendships that go beyond the virtual environment and become enduring, helping to cope with situations ${ }^{(29)}$.

Videos made available on sharing websites, such as YouTube, offer media features that are not usually granted in personal consultations with healthcare professionals. Individuals want to watch, for example, video on types of childbirth and child development, which can involve family members, strengthen existing bonds of affection, and enhance family dynamics ${ }^{(28)}$.

However, health/illness content made available on these websites, such as YouTube, may be of dubious quality. Therefore, individuals need to be guided so that they can analyze, with a critical eye, the information offered or avoid viewing videos posted by lay people ${ }^{(30)}$.

Another tool used for health/illness online information is the blog. In this type of space, experiences are made available, and individuals identify themselves due to the similarity between the situations reported with those that are facing ${ }^{(28)}$. In addition, it allows access to content only for reading, as well as post videos on the subject in health ${ }^{(31)}$.

Research developed in Perth, Australia, with 17 individuals with chronic conditions, explored their needs for health online information. They also verified that patients rely on virtual sources and reflect on the use of data from some sources, such as Wikipedia, which is a portal that allows editing of publications ${ }^{(25)}$. As such, other people can write content that they think is relevant. For this reason, the data on this website are not always correct, and respondents have the need to stick to the author's qualification ${ }^{(25)}$.

Sites, applications, and social media enable individuals to acquire information without request through newsletters, daily notifications, and content updates related to information needs, when they are enrolled, and are users of those resources. In addition, some online means are seen as a source of entertainment, as they enable tools such as sharing images, used by family members, to share pictures of their children on social networks ${ }^{(29)}$.

With regard to the choice of websites, most patients use search tools or random web pages. Some of these visit pages recommended by health professionals, others visit portals indicated by friends and a portion connects websites of pharmaceutical industries. This achievement reinforces individuals' unpreparedness when seeking online information on health/illness ${ }^{(32)}$.

A research shows that family members of children are more accustomed to search portals than to websites developed by health professionals ${ }^{(33)}$. Search engines commonly emphasize partner sources in the first few pages as it is suggested that individuals hardly go beyond the main results page ${ }^{(33)}$.

Participants in this study emphasized the use of Google to find data on health/illness of the preterm and the mother from gestation. However, most family members visit the sources indicated by the research portal, but do not identify or remember the websites where the information was found.

Google is commonly used to look for information on gestation and parenting ${ }^{(29)}$. The data found in the present study are corroborated by a survey of 17 women in Pennsylvania to understand how they use technology during pregnancy. It was evidenced that these use search engines, especially Google. The terms and questions you enter range from those with a few words, such as symptoms, to more specific questions, tailored to your needs ${ }^{(28)}$. No published studies of the same nature were found in Brazilian reality that could confirm or challenge the findings of the present investigation.

A survey of 20 adolescents and young adults with cancer in order to understand how they use the internet and social networks to find information about the illness has found that they access Google and Yahoo to conduct research on treatment, changes in routine caused by the pathology, drugs used and effects of these. However, the technical language used in the websites limited the navigation, because participants declared difficulty in understanding some terms, evaluating how inappropriate to their age groups ${ }^{(34)}$.

Search tools, such as Google, are seen as reliable sources of information and are used as a starting point to find elements relating to health. In the case of Google, it spells spellings in the content described in the search space, and suggests the terms that can be chosen for better search results ${ }^{(25)}$. These findings are emphasized by participants of this study who referred this search tool as the initial marker in their virtual searches, visiting websites, as explained, without concern for the sources consulted, leaving behind the credibility attributed to Google.

Nevertheless, search engines, such as Google, they are usually sponsored by companies that also advertise their products online. Therefore, commercial interests can direct the order of exposure of the websites presented ${ }^{(35)}$. In some cases, as a result of the terms used in the search, results lead users to consult paid platforms such as commercial websites ${ }^{(36-37)}$. 
In the study cited above ${ }^{(29)}$, it was found that some Australian women were aware that the first websites listed on Google are those that pay for the search tool to occupy these positions. They also said that some applications used are sponsored or developed by commercial companies. Therefore they try to be careful in the influence that this data can exert in their researches. Other mothers reported adding advertisements to their social networks after they made pregnancy-related searches.

\section{Study limitations}

Considering the place of recruitment of participants, analysis of the use of online information on health/illness only by parents of preterm infants may be a limitation of this study. Although the other family members entered the NICU to visit the newborns, it was not possible to verify their opinions regarding the presented theme. This aspect can be investigated in future studies.

Another limitation consists of the unique setting in which the participants were, which makes it impossible to make generalizations about the studied object. However, reflections and discussions about the subject can be provoked. Therefore, more extensive investigations with the same public are recommended that extend to other regions of the country.

Studies are suggested that explore how business sponsorship on websites, ad serving, and Google's business correlation may influence family members of preterm infants during surveys.

In addition, health professionals' vision regarding the use of online information by relatives could be investigated, as well as challenges and potentialities that experts face to incorporate virtual technology in the care process.

\section{Contributions to the field of Nursing}

Faced with the impossibility of restricting and controlling the use of the Internet, their discussion in the care process becomes more and more necessary. Therefore, it is essential that educational institutions and health services adopt ways of inserting the theme into their curricula and continuing education, respectively, so that future professionals and those already in the labor market can appropriate of this technology; develop skills; and contribute to the changes in professional practice in line with the resources already used by society, which can contribute to health car improvement.

Professionals need to incorporate into their practice aspects related to the use of online information on health/illness. Therefore, it is essential to know the information needs presented by relatives and/or patients; enable them to use the virtual environment appropriately; improve their relationship with them and, consequently, the care. In order to assist and instruct relatives, it is necessary to know the websites and tools with available health/ illness content to discuss the data credibility offered, as well as positive and negative effects related to their use.

\section{FINAL CONSIDERATIONS}

It was found that the information sought online by parents of premature infants hospitalized in a NICU are diverse and are related to the gestational and postnatal period, focusing on aspects related to maternal and child health. In order to satisfy their informational needs, family members navigate different websites. However, most of the interviewees are unaware, or in some cases do not remember the sources consulted, reporting only the search tool used to find them.

For this reason, it is necessary to make room for dialogue with family members about the information found on the Internet. Initially, one should question what type of content they search for and what doubts exist, and then guide them to access portals that have credibility and provide good information.

Internet impact needs to be taken into account in the dynamics of the relationships between family and health professionals. Knowledge and power over health/illness information are historically the professional's competence, and today, the virtual network provides a world of information of variable quality and easy access. Thus, people can appropriate knowledge through the Internet, influencing adhesion, treatment and care, directing them to their choice regarding their health and the family; this being a relatively new behavior, which needs to be included in the care process.

In this regard, improving access to accurate, secure and reliable information can be done with the collaboration of professionals. In this way, the development of resources that can instruct individuals on how to use the internet to seek health/illness information may result in improvements in the support of relatives of premature infants and other infants admitted to the NICU.

\section{FUNDING}

This research received financial support from Coordenação de Aperfeiçoamento de Pessoal do Nível Superior (CAPES - Coordination of Improvement of Higher Education Personnel).

\section{REFERENCES}

1. Bezner SK, Hodgman El, Diesen DL, Clayton JT, Minkes RK, Langer JC, et al. Pediatric surgery on YouTubeTM: is the truth out there? J Pediatr Surg. 2014;49(4):586-9. doi: 10.1016/j.jpedsurg.2013.08.004

2. Comitê Gestor da Internet no Brasil - CGI.br. TIC domicílios 2015: Pesquisa sobre o uso das tecnologias de informação e comunicação nos domicílios brasileiros [Internet]. São Paulo; 2016 [cited 2016 Nov 5]. Available from: https://cgi.br/media/docs/publicacoes/2/tic_ saude_2015_livro_eletronico.pdf

3. De Rouck S, Leys M. Information behaviour of parents of children admitted to a neonatal intensive care unit: constructing a conceptual framework. Health (London). 2011;15(1):54-77. doi: 10.1177/1363459309360785 
4. Dalton JA, Rodger D, Wilmore M, Humphreys S, Skuse A, Roberts CT, et al. The Health-e Babies App for antenatal education: feasibility for socially disadvantaged women. PLoS ONE. 2018;13(5):e0194337. doi: 10.1371/journal.pone.0194337

5. Globus O, Leibovitch L, Maayan-Metzger A, Schushan-Eisen I, Morag I, Mazkereth R, et al. The use of short message services (SMS) to provide medical updating to parents in the NICU. J Perinatol. 2016;36(9):739-43. doi: 10.1038/jp.2016.83

6. Nicholl H, Tracey C, Begley T, King C, Lynch AM. Internet use by parents of children with rare conditions: findings from a study on parents' web information needs. J Med Internet Res. 2017;19(2):e51. doi: 10.2196/jmir.5834

7. Duggan M, Lenhart A, Lampe C, Ellison NB. Parents and social media [Internet]. Washington: Pew Research Center; 2015 [cited 2016 Oct 30 ]. Available from: http://www.pewinternet.org/2015/07/16/parents-and-social-media/

8. Plantin L, Daneback K. Parenthood, information and support on the internet. A literature review of research on parents and professionals online. BMC Fam Pract. 2009;10:34. doi: 10.1186/1471-2296-10-34

9. Deluca JM, Kearney MH, Norton SA, Arnold GL. Internet use by parents of infants with positive newborn screens. J Inherit Metab Dis. 2012;35(5):879-84. doi: 10.1007/s10545-011-9449-7

10. Laugesen J, Hassanein K, Yuan Y. The impact of internet health information on patient compliance: a research model and an empirical study. J Med Internet Res. 2015;17(6):e143. doi: 10.2196/jmir.4333

11. Patterson RP, Roedl SJ, Farrell MH. Internet searching after parents receive abnormal newborn screening results. J Commun Healthc. 2015;8(4):303-15. doi: 10.1179/1753807615Y.0000000007

12. van der Gugten AC, de Leeuw RJ, Verheij TJ, van der Ent CK, Kars MC. E-health and health care behaviour of parents of young children: a qualitative study. Scand J Prim Health Care. 2016;34(2):135-42. doi: 10.3109/02813432.2016.1160627

13. Oliver-Mora M, Iñiguez-Rueda L. La contribución de las tecnologías Web 2.0 a la formación de pacientes activos. Ciênc Saúde Colet. 2017;22(3):901-10. doi: 10.1590/1413-81232017223.08632015

14. Shroff PL, Hayes RW, Padmanabhan P, Stevenson MD. Internet usage by parents prior to seeking care at a pediatric emergency department: observational study. Interact J Med Res. 2017;6(2):e17. doi: 10.2196/ijmr.5075

15. Tong A, Sainsbury P, Craig J. Consolidated criteria for reporting qualitative research (COREQ): a 32-item checklist for interviews and focus groups. Int J Qual Health Care. 2007;19(6):349-57. doi: 10.1093/intqhc/mzm042

16. Creswell JW. Projeto de pesquisa: métodos qualitativo, quantitativo e misto. $3^{\text {a }}$ ed. Porto Alegre: Artmed; 2015.

17. Camargo BV, Justo AM. Tutorial para uso do software IRAMUTEQ [Internet]. Florianópolis: Universidade Federal de Santa Catarina, Laboratório de Psicologia Social da Comunicação e Cognição; 2016 [cited 2016 Dec 1]. Available from: http://www.iramuteq.org/ documentation/fichiers/Tutorial\%20IRaMuTeQ\%20em\%20portugues_17.03.2016.pdf

18. Sayakhot P, Carolan-Olah M. Internet use by pregnant women seeking pregnancy-related information: a systematic review. BMC Pregnancy Childbirth. 2016;16:65. doi: 10.1186/s12884-016-0856-5

19. Criss S, Baidal JAW, Goldman RE, Perkins M, Cunningham C, Taveras EM. The role of health information sources in decision-making among Hispanic mothers during their children's first 1000 days of life. Matern Child Health J. 2015;19(11):2536-43. doi: 10.1007/s10995-015-1774-2

20. Kurth E, Krähenbühl K, Eicher M, Rodmann S, Fölmli L, Conzemann C, et al. Safe start at home: what parents of newborns need after early discharge from hospital - a focus group study. BMC Health Serv Res. 2016;16:82. doi: 10.1186/s12913-016-1300-2

21. Marski BSL, Custodio N, Abreu FCP, Melo DF, Wernet M. Hospital discharge of premature newborns: the father's experience. Rev Bras Enferm. 2016;69(2):202-9. doi: 10.1590/0034-7167.2016690203i

22. Jones CHD, Neill S, Lakhanpaul M, Roland D, Singlehurst-Mooney H, Thompson M. Information needs of parents for acute childhood illness: determining "what, how, where and when" of safety netting using a qualitative exploration with parents and clinicians. BMJ Open. 2014;4(1):e003874. doi: 10.1136/bmjopen-2013-003874

23. Neill SJ, Jones CH, Lakhanpaul M, Roland DT, Thompson MJ, Ask Sniff Research Team. Parent's information seeking in acute childhood illness: what helps and what hinders decision making? BMJ Open. 2014;18(6):3044-56. doi: 10.1111/hex.12289

24. Park E, Kim H, Steinhoff A. Health-related internet use by informal caregivers of children and adolescents: an integrative literature review. $J$ Med Internet Res. 2016;18(3):e57. doi: 10.2196/jmir.4124

25. Lee K, Hoti K, Hughes JD, Emmerton L. Dr Google and the Consumer: a qualitative study exploring the navigational needs and online health information-seeking behaviors of consumers with chronic health conditions. J Med Internet Res. 2014;16(12):e262. doi: 10.2196/jmir.3706

26. De Rouck S, Leys M. Illness trajectory and Internet as a health information and communication channel used by parents of infants admitted to a neonatal intensive care unit. J Adv Nurs. 2013;69(7):1489-99. doi: 10.1111/jan.12007

27. Chen YY, Li CM, Liang JC, Tsai CC. Health information obtained from the internet and changes in medical decision making: questionnaire development and cross-sectional survey. J Med Internet Res. 2018;20(2):e47. doi: 10.2196/jmir.9370

28. Kraschnewski JL, Chuang CH, Poole ES, Peyton T, Blubaugh I, Pauli J, et al. Paging "Dr. Google": does technology fill the gap created by the prenatal care visit structure? Qualitative focus group study with pregnant women. J Med Internet Res. 2014;16(6):e147. doi: 10.2196/ jmir.3385

29. Lupton D. The use and value of digital media for information about pregnancy and early motherhood: a focus group study. BMC Pregnancy Childbirth. 2016;16:171. doi: 10.1186/s12884-016-0971-3 
30. Stellefson M, Chaney B, Ochipa K, Chaney D, Haider Z, Hanik B, et al. YouTube as a source of chronic obstructive pulmonary disease patient education: a social media content analysis. Chron Respir Dis. 2014;11(2):61-71. doi: 10.1177/1479972314525058

31. Moretti FA, Oliveira VE, Silva EMK. Access to health information on the internet: a public health issue? Rev Assoc Med Bras. 2012;58(6):650-8. doi: 10.1590/S0104-42302012000600008

32. Coelho EQ, Coelho AQ, Cardoso JED. Does the medical information currently available on the Internet affect the physician-patient relationship? Rev Bioét [Internet]. 2013 [cited 2016 Dec 01];21(1):137-44. Available from: http://revistabioetica.cfm.org.br/index.php/ revista_bioetica/article/view/728

33. Pehora C, Gajaria N, Stoute M, Fracassa S, Serebale-O'Sullivan R, Matava CT. Are parents getting it right? A survey of parents' internet use for children's health care information. Interac J Med Res. 2015;4(2):e12. doi: 10.2196/ijmr.3790

34. Domínguez M, Sapiña L. "Others Like Me". An approach to the use of the internet and social networks in adolescents and young adults diagnosed with cancer. J Cancer Educ. 2017;32(4):885-91. doi: 10.1007/s13187-016-1055-9

35. Abenhaim HA, Baazeem M. Google and women's health-related issues: what does the search engine data reveal? Online J Public Health Inform. 2014;6(2):e187. doi: 10.5210/ojphi.v6i2.5470

36. Pentoney C, Harwell J, Leroy G. Does query expansion limit our learning? A comparison of social-based expansion to content-based expansion for medical queries on the internet. AMIA Annu Symp Proc. 2014;2014:976-83. Available from: https://www.ncbi.nlm.nih.gov/ pmc/articles/PMC4419949/

37. Burrus MT, Werner BC, Starman JS, Kurkis GM, Pierre JM, Diduch DR, et al. Patient perceptions and current trends in internet use by orthopedic outpatients. HSS J. 2017;13(3):271-5. doi: 10.1007/s11420-017-9568-2 